\title{
LEVANTAMENTO DAS ESPÉCIES VEGETAIS DAS PRAÇAS DE SÃO JOÃO DOS PATOS - MA
}

\author{
SURVEY OF PLANT SPECIES IN PUBLIC SQUARES OF \\ SÃO JOÃO DOS PATOS - MA
}

\author{
Leana Alves Barbosa ${ }^{1}$, Clarissa Gomes Reis Lopes², Wilza Gomes Reis Lopes ${ }^{3}$
}

\section{RESUMO}

O conhecimento sobre as espécies vegetais introduzidas nos espaços urbanos públicos é importante para o planejamento do cenário paisagístico. Diante disso o objetivo deste trabalho foi realizar um censo das espécies vegetais utilizadas nas praças da cidade de São João dos Patos, Maranhão. Nas 14 praças identificadas foram realizadas visitas para coletar amostras dos vegetais presentes, para posterior quantificação e classificação quanto à espécie, origem e hábito de crescimento. Foram registrados 290 indivíduos pertencentes a 37 espécies. A família com maior riqueza de espécies foi Fabaceae. As espécies mais abundantes foram Heliconia psittacorum L.f. $(17,2 \%)$, Azadirachta indica A. Juss. (11,7\%), Ficus benjamina L. (11,0\%), Mangifera indica L. $(5,9 \%)$ e uma espécie de Arecaceae (5,5\%), que no total representam $50,3 \%$ do total de indivíduos amostrados neste estudo, o que demonstra uma baixa diversidade espécies nas praças de São João dos Patos. Observou-se uma maior quantidade de espécies arbóreas, seguido pelas herbáceas e por último as arbustivas. Apesar da maioria dos indivíduos serem de hábito arbóreo, a quantidade de indivíduos é pequena, o que não é apropriado para uma região de clima quente.

Palavras-chave: Áreas verdes; Vegetação urbana; Plantas exóticas.

\section{ABSTRACT}

Knowledge of plant species in public urban spaces is important for landscape planning. This study aimed to survey the plant species used in plazas of the city of São João dos Patos, Maranhão. In the 14 identified plazas, plant samples were collected for later quantification and identification to species level, origin, and growth habit. There were recorded 290 individuals from 37 species. Fabaceae was the family with the highest species richness. The most abundant species were Heliconia psittacorum L.f. (17.2\%), Azadirachta indica A. Juss. (11.7\%), Ficus benjamina L. (11.0\%), Mangifera indica L. (5.9\%) and one species of Arecaceae (5.5\%) that combined represented $50.3 \%$ of the total individuals sampled in this study. That demonstrates a low species diversity in the plazas of São João dos Patos. Tree species were the most abundant, followed by herbaceous plants and shrubs. Although most individuals were tree species, the quantity of individuals is low, which is not adequate to a region with a hot climate.

Key-words: Green areas; Urban vegetation; Exotic plants.

Recebido em 29.01.2015 e aceito em 15.09.2015

1 Bacharel e Licenciada em Ciências Biológicas pela Universidade Federal do Maranhão, Pós-graduanda em Gestão Ambiental pela Universidade Estadual do Piauí. São João dos Patos, MA. Email: lekbarbosa@hotmail.com

2 Bióloga, Doutora em Botânica pela Universidade Federal Rural de Pernambuco, professora do curso de Licenciatura em Ciências da Natureza e do Mestrado em Desenvolvimento e Meio Ambiente da Universidade Federal do Piauí. Teresina, Piauí. Email: claris-lopes@hotmail.com

3 Arquiteta, Doutora em Engenharia Agrícola, professora do Departamento de Construção Civil e Arquitetura e do Mestrado e Doutorado em Desenvolvimento e Meio Ambiente da Universidade Federal do Piauí. Teresina, Piauí. E-mail: izalopes@uol.com.br 


\section{INTRODUÇÃO}

As cidades são organismos vivos de contínuo crescimento e expansão, sendo atrativas para um número cada vez maior de pessoas, por possibilitarem o acesso a diversos bens e serviços, como também às principais manifestações culturais. São formadas, do ponto de vista físico, por áreas construídas e por espaços livres de construção.

Para Schlee et al. (2009, p. 243), são várias as funções relacionadas aos espaços livres de construção, muitas vezes sobrepostas, destacando-se "a circulação e a drenagem urbanas, atividades de lazer, conforto, preservação, conservação, requalificação ambiental e convívio social". Tais espaços podem assumir no contexto urbano a forma de ruas, praças, largos, pátios, quintais, parques, jardins, terrenos baldios, corredores externos, vilas e vielas.

Entre os espaços livres da cidade, se distinguem os públicos, que são de livre acesso à população, sendo essenciais para a qualidade de vida urbana. Segundo Leite (2011, p. 159), "praças, ruas, jardins e parques, em suas múltiplas funções, constituem o cerne do sistema de espaços livres das cidades", destacando a sociabilidade como uma das mais importantes.

As praças no Brasil colônia, segundo Marx (1980, p. 50), tiveram seu início associadas aos adros das igrejas, sendo local "para reunião de gente e para exercício de um sem-número de atividades diferentes, surgiu entre nós, de maneira marcante e típica, diante de capelas ou igrejas, de conventos ou irmandades religiosas".

No final do século XVIII, surgem as praças como áreas destinadas ao verde. Nesse contexto, com a chegada da família real ao Brasil, aliaram-se espécies nativas e exóticas na jardinagem de ruas e casas. Contudo, vale ressaltar que até o século XIX a vegetação nas cidades brasileiras ainda não era tão relevante, já que a cidade aparecia como forma contrária ao espaço rural. A maior ocorrência de jardins, praças e parques arborizados se deu no início do século XX (GOMES; SOARES, 2003).

A presença de plantas nos espaços urbanos pode desempenhar funções de sombreamento e absorção de parte dos raios solares, amenizando o clima local (ALVES; BIUDES, 2011). Neste sentido, estes autores mostraram a importância das áreas vegetadas para a redução das ilhas de calor, pois podem contribuir para o controle da incidência solar e consequente redução de temperatura durante o dia e aumento da umidade do ar, atuando, ainda, no controle da ação dos ventos e das chuvas. Em estudo realizado na Universidade Federal do Mato Grosso, em Cuiabá, os autores constataram a diferença de mais $3{ }^{\circ} \mathrm{C}$ na média de temperatura encontrada em áreas que apresentavam mais vegetação $\left(35,6{ }^{\circ} \mathrm{C}\right)$ 
em relação às áreas com menor índice de vegetação, cuja média de temperatura chegou a $38,9^{\circ} \mathrm{C}$.

Para Labaki et al. (2011, p. 24), a vegetação tem papel importante nas cidades pois atua "no controle da incidência de radiação solar e do ganho de calor, da umidificação e depuração do ar", contribuindo, dessa forma, para a melhoria da qualidade do ambiente urbano.

Entretanto, é preciso ter o cuidado na escolha das espécies para serem plantadas em espaços públicos, pois o uso incorreto das espécies vegetais traz não só problemas ambientais, mas também pode refletir no prejuízo causado aos usuários e empresas prestadoras de serviços de rede elétrica, telefonia e esgotos (DANTAS; SOUZA, 2004). São comuns os transtornos ocorridos devido à falta de técnicos especializados em arborização, além disso, a falta de informações e pesquisas é outro fator relevante que pode ocasionar muitos conflitos com a estrutura urbana (MIRANDA; CARVALHO, 2009).

Além de observar o espaço destinado à planta e ao seu crescimento, também se deve considerar a sua origem, sendo importante priorizar espécies nativas, pois espécies exóticas podem acarretar na contaminação biológica, que tem como características a perda da biodiversidade, a modificação dos ciclos e características naturais dos ecossistemas atingidos e a alteração fisionômica da paisagem natural, com consequências econômicas vultosas (BIONDI; PEDROSA-MACEDO, 2008). Segundo Medeiros (2014), a vantagem de se utilizar espécies nativas e não espécies exóticas, é que as nativas servem de alimento para a flora local, dificilmente são exterminadas por pragas e servem de abrigo e local de construção de ninhos para os pássaros nativos.

Destaca-se, então, a importância de estudos voltados para a identificação de espécies vegetais utilizadas nas cidades, quantificando a proporção entre nativas e exóticas, tipo e número de espécimes e detectando os problemas existentes, visando subsidiar à gestão municipal na escolha de espécies adequadas para plantio e ainda, em ações direcionadas à manutenção das existentes. Dessa forma, o objetivo deste trabalho foi realizar levantamento das espécies vegetais utilizadas nas praças do município de São João dos Patos, Maranhão e caracterizá-las quanto ao hábito de crescimento e origem.

\section{MATERIAIS E MÉTODOS}

O estudo foi realizado no município de São João dos Patos, Maranhão, conhecido como "Capital dos Bordados". Este município surgiu na primeira metade do século XIX, com o povoamento oriundo de lavradores e criadores procedentes da cidade de Passagem 
Franca. Possui área de 1.500,631 km² localizado na Região Nordeste do Brasil, com o

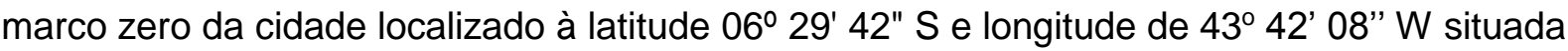
ao leste do estado do Maranhão. Com população estimada, em 2014, de 25.287 habitantes e densidade demográfica de $16,61 \mathrm{hab} / \mathrm{km}^{2}$, tem como principal fonte de renda a produção de grão e frutas e o trabalho das artesãs (bordados). O clima da região, segundo a classificação de Köppen, é tropical (Aw') subúmido seco com dois períodos bem definidos: um chuvoso, que vai de dezembro a maio, e outro seco, correspondente aos meses de junho a novembro (CORREIA FILHO et al., 2011).

Dentre os 16 bairros de São João dos Patos, as 14 praças estão localizadas em 4 bairros (Figura 1). Nestas praças são realizadas atividades esportivas, eventos culturais e festas, sendo, ainda, local de encontro e de concentração de bares e lanchonetes.

Figura 1. Localização das praças estudadas em São João dos Patos, Maranhão Figure 1. Location of the public squares studied in São João dos Patos, Maranhão

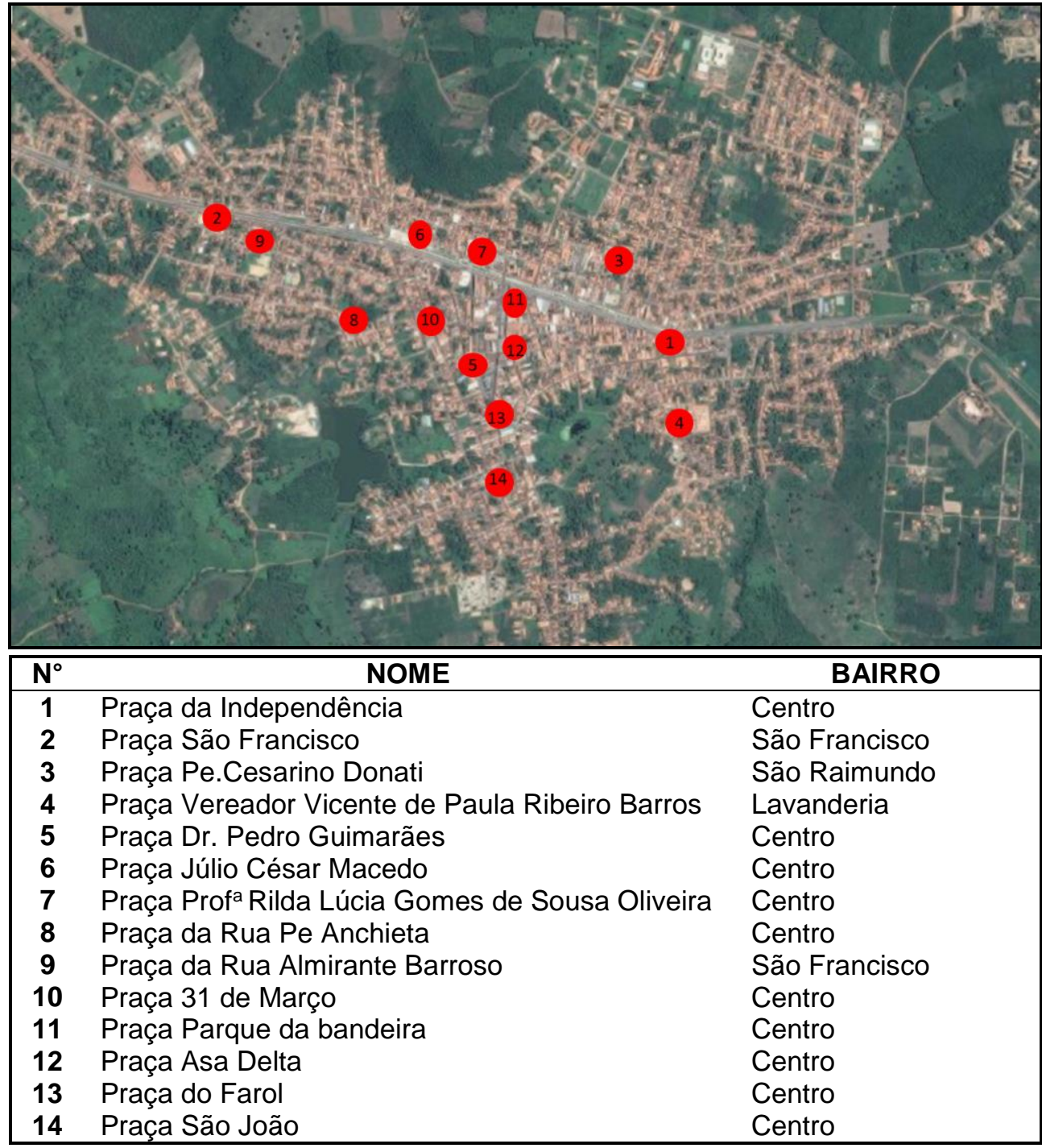


A coleta de dados foi realizada por meio de visitas nas áreas de estudo, no período de agosto a novembro de 2014. Foram inventariadas as 14 praças da cidade, com base nos registros e informações da Prefeitura Municipal de São João dos Patos, identificando as espécies vegetais presentes, com suas respectivas densidades, hábito de crescimento e origem da espécie.

O material botânico foi herborizado, seguindo as técnicas usuais de preparação, secagem e montagem de exsicatas. A identificação taxonômica foi realizada por comparações de exsicatas depositadas no herbário Graziela Maciel Barros (TEPB), da Universidade Federal do Piauí, com o auxílio de chaves taxonômicas e literatura específica.

O material coletado de duvidosa identificação e/ou de difícil identificação foi enviado a especialistas. As espécies foram classificadas segundo o Angiosperm Phylogeny Group III (APG III, 2009). A confirmação da validade do nome das espécies, a abreviação dos nomes dos autores e a classificação das espécies quanto à origem (nativa ou exótica) foram realizadas por meio de consulta à Lista de Espécies da Flora do Brasil (2014). As espécies classificadas como naturalizadas e cultivadas foram consideradas como exóticas neste trabalho.

A frequência relativa das espécies foi calculada dividindo o número de praças em que a espécie foi amostrada pelo total de praças inventariadas (14 praças), multiplicado por 100. A abundância relativa das espécies foi calculada, dividindo-se o número de indivíduos da espécie pelo total de árvores inventariadas em todas as praças, multiplicado por 100 (SANTOS-JUNIOR; COSTA, 2014).

\section{RESULTADOS E DISCUSSÃO}

Nas praças de São João dos Patos foram registrados 290 indivíduos, pertencentes a 37 espécies vegetais e 23 famílias botânicas (Tabela 1). O maior número de espécies foi registrado na família Fabaceae, apresentando quatro espécies: Adenanthera pavonina L., Erythrina variegata L., Delonix regia (Bojer ex Hook.) Raf. e Tamarindus indica L., sendo todas exóticas. Apocynaceae, Cactaceae e Myrtaceae também apresentaram elevada riqueza de espécies com três cada uma. As famílias Fabaceae e Myrtaceae foram também as que apresentaram maior riqueza de espécies nas praças em Sorocaba, São Paulo (CARDOSO-LEITE et al., 2014). Quatro espécies foram identificadas até nível de família, devido a não se encontrar em floração durante o período de estudo (Arecaceae - 2 espécies, Cannaceae e Sapotaceae). 
Tabela 1. Lista das famílias e espécies vegetais encontradas nas praças do município de São João dos Patos-MA, com seus respectivos nomes populares, hábito de crescimento, origem, número de indivíduos, frequência e abundância relativa.

Table 1. List of families and plant species found in the squares of São João dos Patos, Maranhão, with their popular names, growth habit, origin, number of individuals, frequency and relative abundance

\begin{tabular}{|c|c|c|c|c|c|c|}
\hline FAMÍLIA/ESPÉCIE & NOME POPULAR & HÁB & ORIG & NI & $\begin{array}{l}\text { AR } \\
(\%)\end{array}$ & $\begin{array}{l}\text { FR } \\
(\%)\end{array}$ \\
\hline Anacardiaceae & & & & & & \\
\hline $\begin{array}{l}\text { Mangifera indica L. } \\
\text { Apocynaceae }\end{array}$ & Mangueira & Árv. & Exót. & 17 & 5,9 & 42,9 \\
\hline Allamanda angustifolia Pohl & Espirradeira & Arb. & Nat. & 5 & 1,7 & 14,3 \\
\hline Nerium oleander L. & Oleandro & Árv. & Exót. & 5 & 1,7 & 28,6 \\
\hline $\begin{array}{l}\text { Plumeria rubra L. } \\
\text { Asparagaceae }\end{array}$ & Jasmim & Árv. & Exót. & 7 & 2,4 & 21,4 \\
\hline Agave angustifolia Haw & Piteira-do-caribe & Herb. & Exót. & 9 & 3,1 & 7,1 \\
\hline Agave americana L. & Piteira & Herb. & Exót. & 2 & 0,7 & 7,1 \\
\hline Sansevieria cylindrica Bojer ex Hook. & Lança-de-São-Jorge & Herb. & Exót. & 1 & 0,3 & 7,1 \\
\hline $\begin{array}{l}\text { Sansevieria trifasciata Prain } \\
\text { Bombacaceae }\end{array}$ & Espada-de- São Jorge & Herb. & Exót. & 12 & 4,1 & 35,7 \\
\hline $\begin{array}{l}\text { Pachira aquatica Aubl } \\
\text { Cactaceae }\end{array}$ & Mamorana & Árv. & Nat. & 11 & 3,8 & 28,6 \\
\hline Napolea cochenillifera (L.) Salm-Dyck & Cacto & Arb. & Exót. & 3 & 1,0 & 21,4 \\
\hline Pereskia grandifolia Haw. & Cacto-rosa & Arb. & Nat. & 1 & 0,3 & 7,1 \\
\hline $\begin{array}{l}\text { Cereus sp. } \\
\text { Chrysobalanaceae }\end{array}$ & Cacto & Arb. & Exót. & 2 & 0,7 & 7,1 \\
\hline $\begin{array}{l}\text { Licania tomentosa (Benth.) Fritsch } \\
\text { Combretaceae }\end{array}$ & Oiti & Árv. & Nat. & 3 & 1,0 & 14,3 \\
\hline $\begin{array}{l}\text { Terminalia catappa L. } \\
\text { Euphorbiaceae }\end{array}$ & Amendoeira & Árv. & Exót.. & 12 & 4,1 & 35,7 \\
\hline $\begin{array}{l}\text { Codiaeum variegatum (L.) Rumph. ex A. } \\
\text { Juss. }\end{array}$ & Cróton & Arb. & Exót. & 2 & 0,7 & 7,1 \\
\hline $\begin{array}{l}\text { Jatropha gossypiifolia L. } \\
\text { Fabaceae }\end{array}$ & Pião-roxo & Arb. & Nat. & 2 & 0,7 & 7,1 \\
\hline Adenanthera pavonina $\mathrm{L}$. & Tento-Carolina & Árv. & Exót. & 11 & 3,8 & 35,7 \\
\hline Erythrina variegata $\mathrm{L}$. & Eritrina & Árv. & Exót. & 1 & 0,3 & 7,1 \\
\hline Delonix regia (Bojer ex Hook.) Raf. & Flamboyant & Árv. & Exót. & 1 & 0,3 & 7,1 \\
\hline $\begin{array}{l}\text { Tamarindus indica L. } \\
\text { Heliconiaceae }\end{array}$ & Tamarindeiro & Árv. & Exót. & 3 & 1,0 & 14,3 \\
\hline $\begin{array}{l}\text { Heliconia psittacorum L. f. } \\
\text { Lythraceae }\end{array}$ & Heliconia-papagaio & Herb. & Nat. & 50 & 17,2 & 7,1 \\
\hline $\begin{array}{l}\text { Lagerstroemia indica } \mathrm{L} \text {. } \\
\text { Meliaceae }\end{array}$ & Loucura-de-criança & Árv. & Exót. & 1 & 0,3 & 7,1 \\
\hline $\begin{array}{l}\text { Azadirachta indica A. Juss. } \\
\text { Moraceae }\end{array}$ & $\mathrm{Nim}$ & Árv. & Exót. & 34 & 11,7 & 35,7 \\
\hline $\begin{array}{l}\text { Ficus benjamina L. } \\
\text { Musaceae }\end{array}$ & Figueira & Árv. & Exót. & 32 & 11,0 & 71,4 \\
\hline $\begin{array}{l}\text { Musa sp } \\
\text { Myrtaceae }\end{array}$ & Bananeira & Herb. & Exót. & 14 & 4,8 & 7,1 \\
\hline Syzygium cumini (L.) Skeels & Azeitona-preta & Árv. & Exót. & 8 & 2,7 & 14,3 \\
\hline Syzygium jambos (L.) Alston & Jambo & Árv. & Exót. & 1 & 0,3 & 7,1 \\
\hline $\begin{array}{l}\text { Psidium guajava } L \text {. } \\
\text { Nyctaginaceae }\end{array}$ & Goiabeira & Árv. & Exót. & 4 & 1,3 & 21,4 \\
\hline $\begin{array}{l}\text { Bougainvillea spectabilis Willd. } \\
\text { Rubiaceae }\end{array}$ & Buganvília & Arb. & Nat. & 1 & 0,3 & 7,1 \\
\hline $\begin{array}{l}\text { Morinda citrifolia L. } \\
\text { Rutaceae }\end{array}$ & Noni & Árv. & Exót. & 1 & 0,3 & 7,1 \\
\hline $\begin{array}{l}\text { Murraya paniculata ( L.) Jack } \\
\text { Turneraceae }\end{array}$ & Jasmim-laranja & Arb. & Exót. & 1 & 0,3 & 7,1 \\
\hline $\begin{array}{l}\text { Turnera ulmifolia L. } \\
\text { Xanthorrhoeaceae }\end{array}$ & Chanana & Herb. & Exót. & 1 & 0,3 & 7,1 \\
\hline Aloe vera (L.) Burm. f. & Babosa & Herb. & Exót. & 7 & 0,3 & 7,1 \\
\hline
\end{tabular}


As espécies que apresentaram maior frequência relativa nas praças foram: Ficus benjamina (71,4\%), Mangifera indica (42,9\%), Azadirachta indica (35,7\%), Sansevieria trifasciata (35,7\%), Terminalia catappa (35,7\%) e Adenanthera pavonina (35,7\%).

Dentre as espécies mais abundantes, se destacaram Heliconia psittacorum (17,2\%), Azadirachta indica (11,7\%), Ficus benjamina (11,0\%), Mangifera indica (5,9\%) e uma espécie de Arecaceae (5,5\%), que no total representam 50,3\% do total de indivíduos amostrados neste estudo, o que demonstra um predomínio de poucas espécies nas praças de São João dos Patos (MA).

Entre as espécies identificadas, apenas Heliconia psittacorum apresentou mais de 15\% de abundância. Destaca-se que, segundo Milano e Dalcin (2000), o uso de uma espécie nos espaços públicos urbanos não deve ultrapassar a faixa de 10 a $15 \%$ de indivíduos de uma única espécie, pois isso pode facilitar a propagação de pragas e doenças entre as plantas. A alta abundância desta espécie, em uma única praça, provavelmente ocorreu, por ela formar touceiras e apresentar propagação clonal (LORENZI; SOUZA, 2001).

Ficus benjamina foi uma espécie que teve elevada abundância de indivíduos (11\%) em 10 praças de São João dos Patos (MA) e, também, apresentou elevada abundância em outros levantamentos em diversas regiões do Brasil (ASSUNÇÃO et al., 2014; SANTOSJUNIOR; COSTA, 2014; LACERDA; LIRA-FILHO; SANTOS, 2011; SOUZA; CINTRA, 2007). Provavelmente, o uso excessivo de Ficus benjamina na arborização urbana seja influência de um modismo em todo o Brasil (SANTOS-JUNIOR; COSTA, 2014; BARROS; GUILHERME; CARVALHO, 2010). Apesar disso, não é recomendado o seu plantio em espaços públicos. Esta espécie costuma apresentar conflitos com cabos aéreos de telecomunicações e de energia elétrica, além de comprometer as calçadas, devido às raízes aparentes (ASSUNÇÃO et al., 2014; SANTOS-JUNIOR; COSTA, 2014; BARROS; GUILHERME; CARVALHO, 2010).

Já, Azadirachta indica, conhecida popularmente como nim, provavelmente é o novo modismo na região nordeste do país, sendo uma das mais frequentes em diversos locais como no semiárido paraibano (LACERDA; LIRA-FILHO; SANTOS, 2011), em Sobral, Ceará (MENDES; FIGUEREIDO; BRAGA, 2012) e em Timon, Maranhão (MORAES; MACHADO, 2014). Esta espécie é bastante indicada para ambientes com altas temperaturas e tem se adaptado muito bem na região (LACERDA; LIRA-FILHO; SANTOS, 2011).

A praça que apresentou o maior número de indivíduos foi a Praça Doutor Pedro Guimarães, com 93 indivíduos, e o menor número foi na Praça Asa Delta, que apresentou 2 indivíduos. A Praça Doutor Pedro Guimarães, além de apresentar o maior número de indivíduos, também apresentou o maior número de espécies (14), enquanto que, as Praças 31 de Março, Asa Delta e Praça do Farol apresentaram duas espécies vegetais. 
Dos 290 indivíduos amostrados, 192 são indivíduos de espécies exóticas (66,2\%) e 98 de espécies nativas (33,8\%). Das 37 espécies registradas, também houve um maior número de espécies exóticas (70,3\%) comparada as 11 espécies nativas (29,7\%). Dentre as exóticas, destacaram-se quanto à abundância Ficus benjamina, Azadirachta indica, Mangifera indica, Musa sp., Sansevieria trifasciata e Terminalia catappa.

O uso de espécies exóticas pode se tornar um problema quando essas passam a dominar o ambiente e a causar danos às espécies nativas e ao próprio funcionamento dos ecossistemas, pois em muitos casos, as invasões biológicas causam a extinção das espécies nativas (BIONDI; PEDROSA-MACEDO, 2008).

Dentre as espécies nativas, destacam-se quanto à abundância, Heliconia psittacorum, uma espécie de Arecaceae, Pachira aquatica, Canna sp. Embora haja um domínio de espécies exóticas nos espaços públicos urbanos (SANTOS-JUNIOR; COSTA, 2014; BARROS; GUILHERME; CARVALHO, 2010), o uso de espécies nativas é importante, pois elas servem de abrigo e alimento para a fauna local (MEDEIROS, 2014). Além disso, diante da alta degradação das florestas e da fragmentação dos habitats, o uso de espécies nativas no paisagismo urbano pode contribuir para sua divulgação e conservação ex situ, que se refere ao cultivo fora dos perímetros de áreas protegidas, conforme registrado por Silva e Perelló (2010), em estudo no Rio Grande do Sul. Estes autores afirmaram que o plantio de espécies "criticamente em perigo" em uso paisagístico pode contribuir para a conservação ex situ de espécies e que, se essa atividade for bem planejada pode aumentar a variabilidade genética, além de ser uma forma muito eficiente de conservar o banco genético destas espécies.

As espécies nativas Pereskia grandifolia, Bougainvillea spectabilis, uma espécie não identificada pertencente à Arecaceae e outra à Sapotaceae apresentaram baixa frequência, com apenas um indivíduo, tal como as espécies exóticas: Sansevieria cylindrica, Erythrina variegata, Delonix regia, Lagerstroemia indica, Syzygium jambos, Morinda citrifolia, Murraya paniculata e Turnera ulmifolia.

Observou-se ainda um predomínio de espécies arbóreas $(52,8 \%$ do total de indivíduos), destacando-se quanto à abundância Azadirachta indica, Ficus benjamina, Mangifera indica, Terminalia catappa e Adenanthera pavonina. As herbáceas apresentam-se com 11 espécies (41,4\%), destacando-se Heliconia psittacorum, uma espécie de Arecaceae, Musa sp., Sansevieria trifasciata e Agave angustifolia. Os arbustos apresentam-se com 8 espécies (5,9\%), destacando-se Allamanda angustifolia, Napolea cochenillifera, Cereus sp., Codiaeum variegatum e Jatropha gossypiifolia.

A abundância de espécies arbóreas no paisagismo urbano contribui para um maior sombreamento causado pelas copas das árvores, o que torna o local mais agradável, com 
temperaturas mais baixas durante o dia e menor incidência dos raios solares de forma direta, permitindo maior conforto térmico aos frequentadores do local (ALVES; BIUDES, 2011; LUNDGREN et al., 2014), o que é muito importante para locais de clima quente.

Foi observado o uso de algumas espécies vegetais, como Mangifera indica, Terminalia catappa e Delonix regia, em locais não compatíveis com o porte dessas espécies, o que resultou em danos aos canteiros e calçamentos, refletindo a falta de planejamento e conhecimento sobre as espécies vegetais utilizadas na arborização da cidade, pois tais espécies necessitam de mais espaço para seu crescimento e desenvolvimento. Em contrapartida, em algumas das praças estudadas houve melhor planejamento do projeto paisagístico e, consequentemente, foi observada uma estrutura dos canteiros com espaços maiores, com melhores condições de suportar árvores de grande porte, além da realização de poda regular, que evita o crescimento exagerado do vegetal.

\section{CONCLUSÕES}

As praças da cidade de São João dos Patos possuem baixa riqueza de espécies e densidade de indivíduos, necessitando da inserção de mais plantas, tanto arbóreas como herbáceas. As espécies vegetais utilizadas são, em sua maioria, arbóreas e exóticas, destacando-se Azadirachta indica e Ficus benjamina, que apresentam grande abundância em outros levantamentos, possivelmente por um modismo em diversos locais do Brasil.

O uso excessivo de plantas exóticas em um país dotado de flora bastante rica e diversa é no mínimo contraditório. Dessa forma, é importante o desenvolvimento de políticas voltadas para a valorização e inserção de espécies nativas nas praças e ruas das cidades brasileiras, e inclusive de pesquisas para a descoberta de novas espécies com potencial paisagístico e o seu manejo no ambiente urbano.

Conhecer as espécies, o porte e a origem dos vegetais constituem-se em aspecto relevante no planejamento dos espaços urbanos, que tenham como foco a apropriação pela comunidade, tanto considerando o aspecto visual proporcionado pelo verde como pela melhoria nas condições externas decorrente da redução das temperaturas ambientais

\section{REFERÊNCIAS}

ALVES, E. D. L.; BIUDES, M. S. Os microclimas da Universidade Federal de Mato Grosso/Cuiabá. Revista RA'E GA, Curitiba-PR, v. 23, p. 600-620, 2011. 
APG III. An update of the Angiosperm Phylogeny Group classification for the orders and families of flowering plants: APG III. Botanical Journal of the Linnean Society, Londres, v. 161, n. 2, p. 105-121, 2009.

ASSUNÇÃO, K. C.; LUZ, P. B.; NEVES, L. G.; PAIVA-SOBRINHO, S. Levantamento quantitativo da arborização de praças da cidade de Cáceres/MT. Revista da Sociedade Brasileira de Arborização Urbana, Piracicaba-SP, v. 9, n. 1, p. 123-132, 2014.

BARROS, E. F. S.; GUILHERME, F. A. G.; CARVALHO, R. S. Arborização urbana em quadras de diferentes padrões construtivos na cidade de Jataí. Revista Árvore, Viçosa-MG, v. 34, n. 2, p. 287-295, 2010.

BIONDI, D.; PEDROSA-MACEDO, J. H. Plantas invasoras encontradas na área urbana de Curitiba (PR). Floresta, Curitiba-PR, v. 38, n. 1, p. 129-144, 2008.

CARDOSO-LEITE, E.; FARIA, L. C.; CAPELO, F. F. M.; TONELLO, K. C.; CASTELLO, A. C. D. Composição florística da arborização urbana de Sorocaba/SP, Brasil. Revista da Sociedade Brasileira de Arborização Urbana, Piracicaba-SP, v. 9, n. 1, p. 133-150, 2014.

CORREIA FILHO, F. L.; GOMES, E. R.; NUNES, O. O.; LOPES-FILHO, J. B. Projeto cadastro de fontes de abastecimento por água subterrânea, estado do Maranhão: relatório diagnóstico do município de São João dos Patos. Teresina: CPRM - Serviço Geológico do Brasil, 2011. 31p.

DANTAS, I. C.; SOUZA, C. M. C. Arborização urbana na cidade de Campina Grande - PB: inventário e suas espécies. Revista de Biologia e Ciências da Terra, Campina Grande-PB, v. 4, n. 2, 2004.

GOMES, M. A. S.; SOARES, B. R. A vegetação nos centros urbanos: considerações sobre os espaços verdes em cidades médias brasileiras. Estudos Geográficos, Rio Claro-SP, v. 1, n. 1, p. 19-29, 2003.

LABAKI, L. C.; SANTOS, R. F.; BUENO-BARTHOLOMEI, C. L.; ABREU, L. V. A. Vegetação e conforto térmico em espaços urbanos abertos. Fórum Patrimônio, Belo Horizonte-MG, v. 4, n. 1, p. 23-42, 2011.

LACERDA, R. M. A.; LIRA-FILHO, J. A.; SANTOS, R. V. Indicação de espécies de porte arbóreo para a arborização urbana no semiárido paraibano. Revista da Sociedade Brasileira de Arborização Urbana, Piracicaba-SP, v. 6, n. 1, p. 51-68, 2011.

LEITE, M. A. F. P. Um sistema de espaços livres para São Paulo. Estudos Avançados, São Paulo-SP, v. 25, n. 71, p. 159-174, 2011.

LISTA DE ESPÉCIES DA FLORA DO BRASIL. Jardim Botânico do Rio de Janeiro. Disponível em: <http://floradobrasil.jbrj.gov.br/>. Acesso em: 20 ago. 2014.

LORENZI, H.; SOUZA, H. M. Plantas ornamentais no Brasil. Nova Odessa: Instituto Plantarum Estudos Flora, 2001. 1120 p.

LUNDGREN, W. J. C.; SILVA, L. F.; AMORIM, T. L.; SILVA, K. P. S. Análise da temperatura do solo abaixo da copa de três espécies de árvores na cidade de Serra Talhada - PE. Revista da Sociedade Brasileira de Arborização Urbana, Piracicaba-SP, v. 9, n. 4, p. 1-21, 2014. 
MARX, M. Cidade brasileira. São Paulo: Melhoramentos, 1980.

MEDEIROS, J. A. Arborização urbana com plantas nativas na seca de 2013 na cidade de São José do Seridó/RN. Revista eletrônica em Gestão, Educação e Tecnologia Ambiental, Santa Maria-RS, v. 18, n. 2, p. 908-918, 2014.

MENDES, E. N.; FIGUEREIDO, M. F.; BRAGA, P. E. T. Flora arbustiva/arbórea nos bairros Betânia e Derby na cidade de Sobral, Ceará. Revista Homem, Espaço e Tempo, Sobral, ano VI, n. 1, 2012. Não paginado.

MILANO, M. S.; DALCIN, E. Arborização de vias públicas. Rio de Janeiro: LIGHT, 2000.

MIRANDA, T. O.; CARVALHO, S. M. Levantamento quantitativo e qualitativo de indivíduos arbóreos presentes nas vias do bairro da Ronda em Ponta Grossa-PR. Revista da Sociedade Brasileira de Arborização Urbana, Piracicaba-SP, v. 4, n. 3, p. 143-157, 2009.

MORAES, L. A.; MACHADO, R. R. B. A arborização urbana do município de Timon/MA: inventário, diversidade e diagnóstico quali-quantitativo. Revista da Sociedade Brasileira de Arborização Urbana, Piracicaba-SP, v. 9, n. 4, p. 80-98, 2014.

SANTOS-JUNIOR, A.; COSTA, L. M. Espécies empregadas na arborização urbana do bairro Santiago, JI-Paraná/RO. Revista da Sociedade Brasileira de Arborização Urbana, Piracicaba-SP, v. 9, n. 1, p. 78-91, 2014.

SCHLEE, M. B.; NUNES, M. J.; REGO, A. Q.; RHEINGANTZ, P.; DIAS, M. A. Sistema de espaços livres nas cidades brasileiras: um debate conceitual. Paisagem Ambiente, São Paulo-SP, n. 26, p. 225-247, 2009.

SILVA, J. G.; PERELLÓ, L. F. C. Conservação de espécies ameaçadas do Rio Grande do Sul através de seu uso no paisagismo. Revista da Sociedade Brasileira de Arborização Urbana, Piracicaba-SP, v. 5, n. 4, p. 01-21, 2010.

SOUZA, R. C.; CINTRA, D. P. Arborização viária e conflitos com equipamentos urbanos no bairro da Taquara, RJ. Floresta e Ambiente, Rio de Janeiro-RJ, v. 14, n. 1, p. 25-33, 2007. 